\title{
SMART PROTECTIVE SYSTEM OF ELEVATORS
}

\author{
Rajendra B. Sadafale \\ Professor, Department of Electrical Engineering, SITRC \\ Savitribai Phule Pune University, Nashik
}

Aniket S. Hissal

Student, Department of Electrical Engineering, SITRC Savitribai Phule Pune University, Nashik

\begin{abstract}
An Elevator or lift is a type of vertical cable transportation machine i.e. car that moves people or fright between floors, levels of building. Elevators are powered by electric motor that drive traction cables and counterweight systems. In today's stressful life, everyone needs an easy and convenient way to reach their goals, but there are many obstacles in the easy path. The elevator is also a part of same concept, we choose the elevator route to get our place early, but how safe is the elevator? Of course there is a lot of risk involved. The elevator thread can be broken and falls are among the most common cause of serious injuries and deaths. This paper explains about the fall protection, backup system, operation of elevator using IoT.
\end{abstract}

Keywords- Elevator, Thread Break, Backup system, Limit Switches, Solenoid Locks.

\section{INTRODUCTION}

The elevator is also called as lift that moves a vertical thread attached with car to carry passengers or goods between floors, levels of multistoried buildings. All the modern elevators are propelled by electric motors. The first electric elevator was developed by the German inventor Werner Von Siemens in 1880 and successfully installed in 1889. Elevators have undergone many changes since then.

Due to the cause of rapid population growth of the cities and multistoried building, the need of elevators is being increased and hence the elevator has been one of the important tool of everyone's daily life. People think of safety while travelling in elevator, and some of them don't even travel in the elevator for the fear that the elevator will collapse down.

Of Course the elevators are hundred percent safe, it having some risks. The elevator cable can be broken and falls are among the most common cause of serious injuries and deaths. Due to power failure one can get stuck between the two floors in the elevator. If any fault occurs, it can take a long to identify the exact location. These are some major problems with elevators and can be minimized by proper design, good quality material, maintenance at regular intervals.

\author{
Rahul V. Joshi \\ Student, Department of Electrical Engineering, SITRC \\ Savitribai Phule Pune University, Nashik \\ Rohit M. Bachchhe \\ Student, Department of Electrical Engineering, SITRC \\ Savitribai Phule Pune University, Nashik
}

This paper mainly focuses on the issues of existing elevator system in which there must be provided with protective system which will ensure the safety of people and goods. The deployment of automation to the elevator systems reduces the wait time to increase efficient management of the traffic in residential, commercial and institutional buildings. The improvement in management at these facilities with the incorporation of automated solutions has driven the elevator automation market. To overcome the mentioned issues the protective system named "Smart Protective System of Elevators" which will operate under unusual conditions.

During this Corona Epidemics one must avoid touching anything at public places, in the same way touching the elevator buttons at public places can spread the disease. By considering this IoT technology is used in this project, using which user can call the lift whenever required through android "Blynk" app. In addition to this limit switch sensors are used on the lift and solenoid lock will be placed on the nearby floors, so as to hang the lift in nearby floors to avoid the collusion. Battery is used as backup system results no one can stuck between two floors due to power failure.

\section{LITERATURE SURVEY}

In [1] the paper title "international journal of advance research in Electrical, Electronics and instrumentation engineering”, authors Omkar M. shete, Divyani V. Shete, Saurabh G. Pise. In this paper the author introduced about the structure of elevator control system, design and its simulation using PLC simulation software. The main intension is to replace the traditional relay logic elevator control system with modern PLC based control system. It uses ladder diagram logic for interfacing of various sensors. The paper explains about the $\mathrm{AC}$ motor which is used to drive the elevator cabin and is automated using PLC, circuit diagram and development of ladder logic. Author concluded that the PLC based control system for elevator works better than the other control systems. The flow chart of operation, development of hardware and software for interfacing PLC with elevator is also explained by authors in this paper. 
"International journal of advance research in Electrical, Electronics and Instrumentation engineering”, Design and control of three floor elevators for smart city applications is explained by authors in this paper. Elevators ease the work of human beings and keep them in comfort zone. For the stimulation of proposed system the ladder logic programming is used. Authors concluded that better, faster, stronger and good quality elevators are produced by using PLC, for this design of an elevator control is much more important.

In [2] the paper titled "International journal of advanced research in Computer and Communication engineering ISO 3297:2007 certified", Authors Shri Madhwa Vadiraja institute of technology and management, Udupi, India. How proposed system can be extended for synchronization of multiple elevators operating at the same time is described by the authors. This paper focuses on more number of people can be served in a lesser time results one will be able to spend his/her valuable time on other important matters instead of wasting time on waiting for elevators. In this system wireless sensors are used to detect and transmit information on a number of people requesting elevator transport. This information is analyzed by smart elevator to select or determine one or more transport paths for elevators to follow and is beneficial for person awaiting elevator service.

Thomas D. Barkand. “Elevator Safety: Give The Miner Brake”. U.S. Department of labor Mine safety and health administration, Bruceton safety technology Centre. Paper author explains about the security system having one smart card to active elevator car buttons. Only after brushing the authorized card, the passenger can take the elevator to his home floor. Visitors can control the elevator via visitor automatic controller not by using the smart card.

The paper title [1] "International Journal of advance research in Electrical, Electronics and Instrumentation engineering", Author ${ }^{[1]}$ introduced fully automated elevator using PLC. Ladder logic is used to program a PLC. Previously in [1] author used relay and IC boards for controlling of elevator but by considering its inconvenience now it is replaced by PLC.

\section{STATEMENT OF PROBLEM}

A. In existing system elevator safety is not provided. If thread in the elevator breaks, then the whole gets collapsed heavily due to which human life gets a risk of little damage.

B. Also the second problem is if electric supply is cut off, then the lift stops at the half of the floor so one cannot open the door and operate the lift until the returning of power supply.

\section{OBJECTIVES OF STUDIES AND MOTIVATION}

\section{Objectives:}

A. To design a smart elevator system using wireless sensor network.

B. To design the program (software) for the overall system according to the elevator dispatching algorithm.

C. To integrate the hardware and software in order to simulate the functions of a basic lift system.

\section{CURRENT TECHNOLOGY}

Before creating new technology it is important to consider what technology is currently used to protect the Elevator. Safety breaks, Fire emergency system, Hoist way safety switches, Sensors for automatic shutdown if any failure of component occurs, Alarm switches and many such items are used for Elevator protection system. There are two important things that need to be addressed in mentioned are Fall protection, Backup system for power failure.

\section{1) Elevator Emergency Automatic Rescue Device}

"Elevators emergency automatic rescue device" is a unique tool set up in an elevator that is best used all through an occasion of a electricity failure. An elevator touchdown on emergency is beneficial for stopping passengers from turning into trapped inner an elevator for the duration of electricity failure.

\section{Working}

ARD is the main safety system which rescues passenger in case of power failure. ARD is battery operated device which is acts upon electricity failure, the elevator geared up with this tool mechanically actions and prevents form stacking between floors.

\section{2) Elevator Safety Brake}

Elevators have two or three variety of brakes. If there is any glitch with inside the protection chain, a clamp closes at the pulley above the car, stopping the elevator from mounting. Unlike a car brake, which needs to be depressed to engage, the elevator brake is clamped down until energy is provided to launch it. In that manner any lack of energy, either because of device mistakes or an electricity failure, will activate the brakes.

\section{Working}

If the sensor observe that the elevator is dashing downward, it jams a metallic brake from beneath the elevator right into a channel with inside the guide rails, the metallic rods alongside which the elevator travels. Friction builds among the wedge and the rail, which brings the elevator to prevent at particular rate.

\section{Why Not Succeed}


There are many advantages of currently used system but there are some limitations of the protection system. In recent system which is ARD kit, 6 Batteries of 12 Volt are connected in series for power supply in case of blackout. One of the main limitation is that it requires high cost for uninterrupted power supply (UPS). As per the Batteries usage, batteries have to be recharge within certain period of time. Instead of using in small buildings, apartments the ARD is used in large buildings and vast structured complexes.

Elevator safety breaks are better works in skyscraper shaft i.e. it is also used for more heighted buildings. Break drivers as well as advance supervision panel is used which surely increases the total cost.

\section{USE OF PROPOSED SYSTEM}

The global smart elevator market is segmented on the basics of solutions, applications and geography. Different devices such as biometrics, sensors, motors drivers, keypads, smart cards, visitor management system and many more are used in controlling management system of elevators. As building height rose more number of elevators with speed car needs to install. Technology incorporated are digital security control system, touch screen, battery backup, alarm, break system, speed sensors, which are also the parts of the elevator control system. As large number of elevators busy actions, frequent failure and little maintenance personnel, which will bring the personal and property hazards. The elevator's safe issues has become a common concern. To improve the safety of elevator, regular maintenance is of particular importance.

\section{BLOCK DIAGRAM}

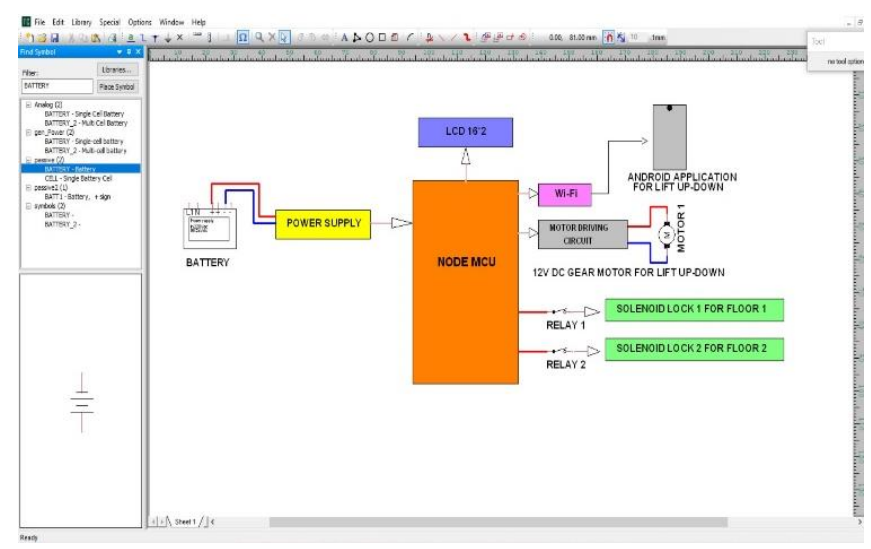

Fig. 1 System Architecture

System architecture contains Node MCU, relays, battery, power supply, display, motor driver, wifi, sensors, solenoid locks, etc. Node MCU is the very important part of the system which one can call the heart of the system. All the branch devices are interconnected with node MCU. Power supply as well as battery works as source for the overall system. Supply is taken from battery as backup if there is power cut off. For the purpose to limit or stop anything limit switch sensors are used which are of four types i.e. whisker, roller, lever, plunger, in addition to this it also can be classified as normally open/normally closed and single pole double throw/double pole single throw.

Along with the information of floor level, LCD display $16 \times 2$ used to reflect the results such as temperature level, humidity and moisture as well. Motor driving circuit used to control the motor and having special feature to drive two motors simultaneously. A $12 \mathrm{~V}$ DC gear motor connected via motor driving circuit used to up and down operation of elevator car. Solenoid locks used for safety reasons and functions to hold the car at floor without falling on ground if thread gets break. Android application also controls the Up/Down operation of elevator without actually touch to the elevator buttons. The whole operation is done through wifi connectivity.

\section{NODE MCU:}

The starting of motor is being from Node MCU, It is one of the best microcontroller plus Wi-Fi module. A node MCU having CP2102 Wi-Fi board which is all in one microcontroller in addition with Wi-Fi platform. The project based on Wi-Fi and IoT requires node MCU. ESP8266 Wi-Fi module with the ESP-12 SMD footprint are specifications of the board. Along with it it has USB to serial chip uploaded codes, logic level converter circuit and $3.3 \mathrm{~V}$ regulator, it helps to uploads code easily and connects the circuit. Node MCU has 16 digital input/output pins.

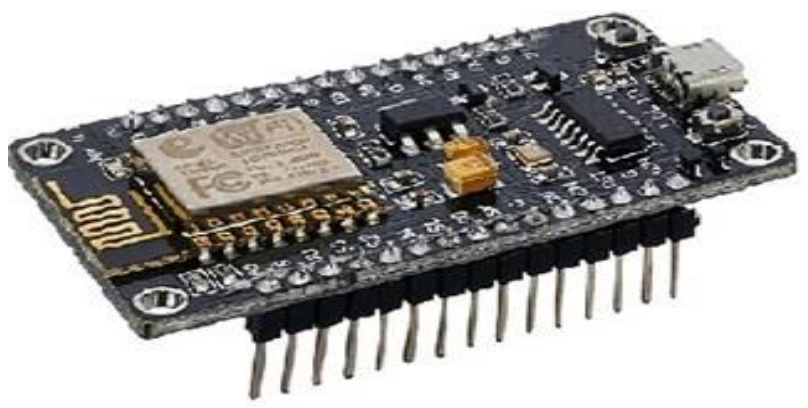

Fig. 2 Node MCU

\section{Features:}

1) Operating Voltage is 3.3 Volt.

2) Input/Output Pins: 16.

3) Input Voltage is 7.12 Volt.

4) Analog to Digital Pins: 1

5) Universal asynchronous Receiver Transmitter: 1

\section{BATTERY:}




\section{International Journal of Engineering Applied Sciences and Technology, 2021}

Vol. 6, Issue 1, ISSN No. 2455-2143, Pages 206-213

Published Online May 2021 in IJEAST (http://www.ijeast.com)

The battery used is lithium-ion manufactured by Samsung titled Lithium-ion 18650. A single battery is having rated voltage of 3.7 Volts and capacity of $2600 \mathrm{mAh}$. In this project three batteries are in series and these are used to supply power to whole project.

\section{Features:}

1) Nominal Voltage is $4.63 \mathrm{~V}$.

2) Charging voltage is $4.20 \mathrm{~V}$.

3) Minimum Charging Current: $2600 \mathrm{~mA}$.

4) Cut-off Voltage (Discharge): $2.75 \mathrm{~V}$

5) Nominal Capacity is $2600 \mathrm{mAh}$.

6) Minimum Capacity is $2550 \mathrm{mAh}$.

\section{RELAY:}

The relay used in this project is 5 Volt Isolated Relay module. To protect the circuit from unusual conditions like short circuit on relay side the optocoupler is used between relay and control unit. BC547 transistor used to drive the relay safely and is triggered by optocoupler IC.

\section{Features:}

1) This relay module can control both AC and DC appliances. Example: Lights, Motors, Fans, etc.

2) Screw terminals like Closed (C), Normally Closed (NC), and Normally Open (NO) are used for quick and easy operation.

3) Coil Voltage is 5 Volt.

\section{LIMIT SWITCH:}

The limit switch is an electromechanical device. The work of limit switch is to stop or limit anything which is in moving state. If there is free fall occurs in the lift i.e. of lift car the limit switch gets detect and give message to the sensors via Node MCU. It actually consist of an actuator which is mechanically link to set of contacts and which is mainly used to controlling machine which is part of control system and ask for safety lock.

\section{SOLENOID LOCKS:}

Solenoid locks is very important safety device used in the project which can be easily interfaced with any Microcontroller, Ardunio. Solenoid lock is a locking device and its usages change according to situation. This are simply electromagnets and made up of big coil copper wire with armature in the middle. When coil is energized the armature pulled at the center of coil.

\section{Features:}

1) Rated Voltage is $12 \mathrm{~V} \mathrm{DC}$.

2) Rated Current is $0.80 \mathrm{~A}$.

3) Power: $9.6 \mathrm{~W}$.

4) Time taking to unlock: 1 Sec.

5) Holding Force: $0.25 \mathrm{Kg}$.

6) Weight is $150 \mathrm{gm}$.

7) Length of Cable Attached: $20 \mathrm{~cm}$.

\section{MOTOR:}

It is a simple DC motor attached with gearbox having RPM 3.5 and rated voltage is 12 Volts. This motor having hole in the middle of shaft and this motor is simple to connect it with wheels and other mechanical parts.

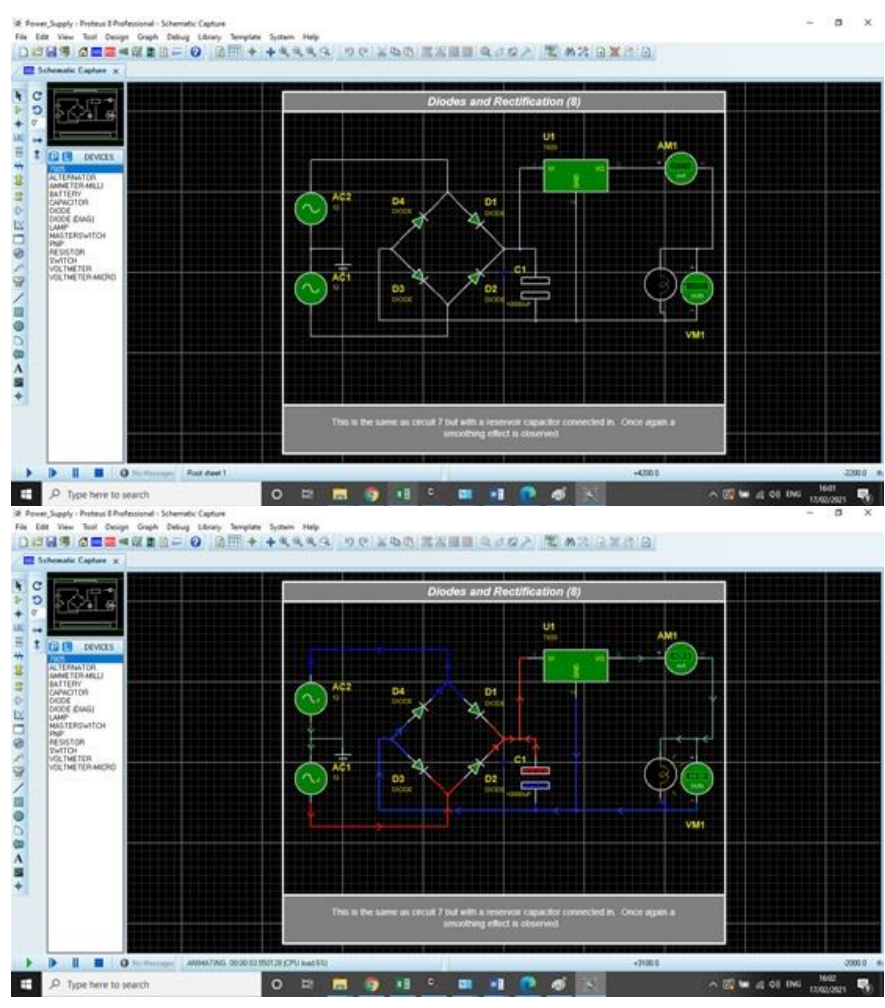

Fig 3 Simulation Screenshot of DC Motor

\section{Features:}

1) User Friendly.

2) RPM: 3.5 .

3) Rated Torque: 14.

4) No Load Current: $60 \mathrm{~mA}$.

5) Load Current: 0.3 A. 
6) Operating voltage is $12 \mathrm{~V}$.

7) Large variety of RPM available

\section{SOFTWARE REQUIREMENTS}

\section{ALTIUM:}

Altium is used in this project for designing of PCB. Basically Altium is electronics design software for engineers which is Australian owned software company. It having some special features like powerful design reuse tool, Real time cost estimation and tracking, Dynamic supply chain intelligence, etc.

\section{ARDUINO IDE:}

The arduino software is used to program the arduino UNO. From tools menu select the option "Adruino UNO w/ATmega328", it comes with preburned bootloader that allows user to upload new code without using external hardware programmer. STK500 protocol is used by it to communicate.

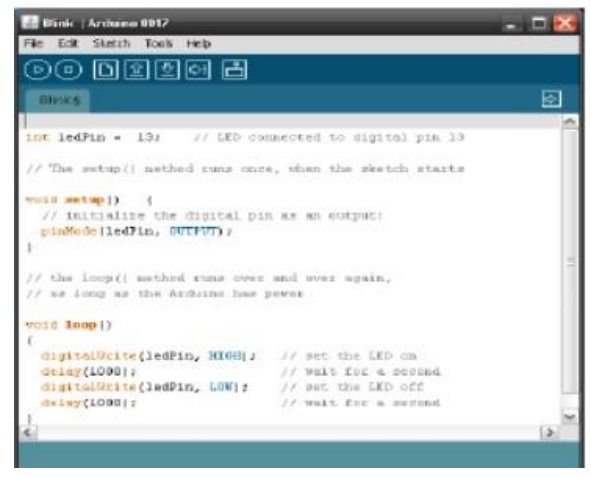

Fig. 4 Arduino Window

\section{OrCAD:}

For electronic design automation (EDA), OrCAD is the software tool used primarily. To manufacture printed circuit boards from electronic schematics and electronic prints, design engineers and electronic technicians mainly used the OrCAD software. The OrCAD is the combination of words Oregon + CAD. Various automations features for PCB design, board level analysis and design rules check, etc. are included in PCB designer. Geometric shapes, curved PCB tracks, ground planes are may be included in design. In this project OrCAD is mainly used for block diagram designing.

\section{BLYNK APP:}

Blynk is the android application which is easily available on playstore and is actually used to design internet of things (IoT). Hardware is remotely controlled by it via $\mathrm{Wi}-\mathrm{Fi}$ connection. It can store the real time data for further use as well as display the sensor data. The blynk app allows user to control and monitor the project hardware from android or ios devices. It is the mode of communication between user and project hardware.

\section{HARDWARE DESIGN \& IMPLEMENTATION}

\section{DESIGNING OF POWER SUPPLY:}

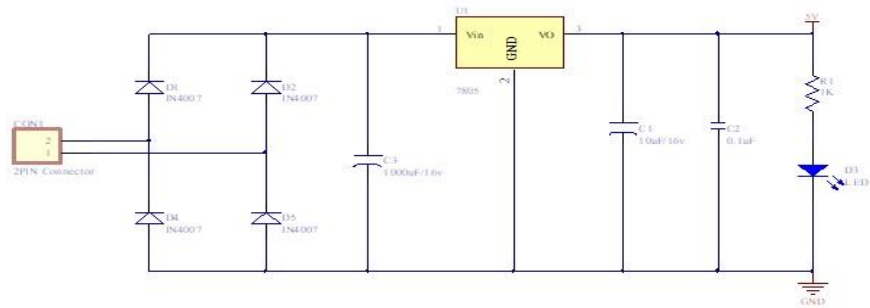

Fig. 5 Power Supply Design

To design the transformer the designer must know the information:

1) Power output

2) Operating Voltage

3) Frequency Range

4) Efficiency and Regulation

Consideration of size of core is much important for the weight and volume of transformer. Generally the formula given is used to find the area of the core.

$$
\mathrm{Ac}=\sqrt{ } \mathrm{Wp} / 0.87
$$

Where,

$$
\begin{aligned}
& \mathrm{Ac}=\text { Area of cross section }(\mathrm{Sq} . \mathrm{Cm}) \\
& \mathrm{Wp}=\text { Primary Wattage. }
\end{aligned}
$$

This project requires $+5 \mathrm{~V}$ output and hence rating of secondary is 9 Volt, $500 \mathrm{~mA}$.

By considering this, Secondary wattage is

$$
\begin{aligned}
\mathrm{Ws} & =9 \times 500 \\
& =4.5 \mathrm{Watts}
\end{aligned}
$$

Therefore,

$$
\begin{aligned}
\text { Ac } & =\sqrt{ } 4.5 / 0.87 \\
& =2.43 \text { Sq. Cm. }
\end{aligned}
$$

\section{TURNS PER VOLT}

The below formula used to determine turns per volt of transformer.

$100000 / 4.44 \times \mathrm{f} \times \mathrm{Bm} \times \mathrm{Ac}$ 
Where,

$$
\begin{aligned}
& \mathrm{f}=\text { Frequency }(\mathrm{Hz}) \\
& \mathrm{Bm}=\text { Density }(\mathrm{Wb} / \mathrm{Sq} . \mathrm{Cm}) \\
& \mathrm{Ac}=\text { Area of cross section. }
\end{aligned}
$$

Turns per volt $=50 / \mathrm{Ac}$

$$
\begin{aligned}
& =50 / 2.43 \\
& =20.576
\end{aligned}
$$

Primary winding turns $=230 \times 20.576=472.48$

Secondary winding turns $=9 \times 20.576=185.184$

\section{SIZE OF WIRE:}

The size of wire is fully depends on the current density. For our transformer current density is $3.1 \mathrm{Amp} / \mathrm{Sq} . \mathrm{mm}$. Size gauge of wire $1.6 \mathrm{Amp} / \mathrm{Sq} . \mathrm{mm}$ or $2.4 \mathrm{Sq} . \mathrm{mm}$ are generally used for less copper loss.

RMS voltage at secondary of transformer is 9 Volt and maximum voltage at secondary is

$$
\begin{aligned}
\text { VRMS } & =V p / \sqrt{ } 2 \\
& =9 / 1.141 \\
& =7.88 \text { Volt }
\end{aligned}
$$

\section{DESIGN OF FILTER CAPACITOR:}

The filter capacitor is calculated by

$$
\mathrm{C}=1 / 4(\sqrt{ } 3 \times \mathrm{r} \times \mathrm{F} \times \mathrm{R} 1
$$

Where,

$\mathrm{r}=$ Presence of ripple in output.

$\mathrm{F}=$ Frequency

$\mathrm{R} 1=\mathrm{I} / \mathrm{P}$ Impedance of Voltage Regulator.

$$
\begin{gathered}
\mathrm{C}=1 / 4(\sqrt{ } 3 \times 0.1 \times 50 \times 28) \\
=1030 \mu \mathrm{F}
\end{gathered}
$$

Here we choose $1000 \mu \mathrm{F} / 25 \mathrm{~V}$ Filter Capacitor.

\section{DESIGNING OF PCB:}

Technology and design are the topics covered in printed circuit boards which is commonly known as PCB in short. Depending upon the conductive circuit pattern the printed circuit boards (PCB) can be classified as single side PCB and double side PCB. Copper, brass, aluminum are the materials widely used to design the PCB. Current carrying capacity needs to select the thickness of conducting materials. Functions of $\mathrm{PCB}$ are as follows:

1) Provide the mechanical strength to the components mounted on it.

2) Electrical interconnections are provided.

3) Used to remove the heat generated in the circuit and hence worked as heat sink.

\section{Designing Parameters of PCB:}

$\rightarrow$ PCB Painting (Done with oil paint)

$\rightarrow$ PCB Drafting (Primarily sketching is done through pencil, carbon paper and trace paper. To remove oxide layer on copper clad the sand paper is used.)

$\rightarrow$ PCB Etching (the board needs to dry and checked after painting. Etching process is required to remove unwanted copper which is present on copper clad. For etching process $\mathrm{FeCl}_{3}$ solution is used.)

$\rightarrow$ PCB Drilling (Hand drill or power drill is used for drilling process. Mostly $0.8 \mathrm{~mm}$ to $0.1 \mathrm{~mm}$ drilling bits are used.)

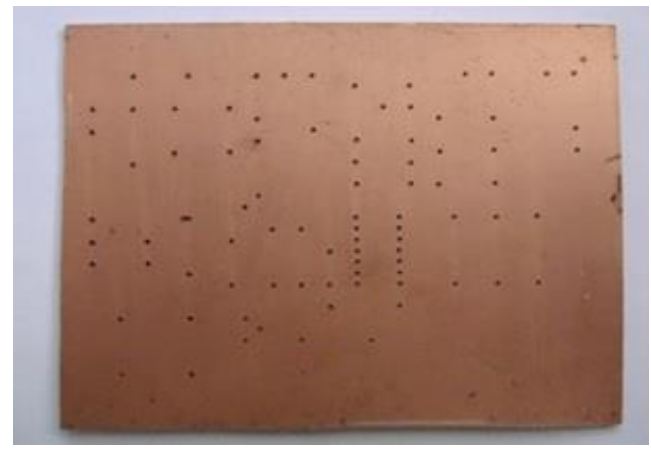

Fig. 6 Printed Circuit Board Designing

$\rightarrow$ PCB Cleaning and Trimming (The layer of $\mathrm{FeCl}_{3}$ is removed in cleaning process with the help of running water. After this process the board is ready to mount the components. After mounting the solder joints are inspected.)

Manufacturing process of PCB can be done through:

1) Photoresist printing (A photoresist is a light sensitive material used to form a coating on surface, which is perfectly patterned.)

2) Screen Printing (Screen printing is used to print graphics, marks, conductive ink on to the foil and panel.)

\section{Requirements:}

1) Good resolution and light sensitivity.

2) Cost should be less. 
3) After unwanted copper is removed it should have possibility to strip.

\section{SOLDERS AND SOLDERING TECHNIQUES:}

Solders are the electric joints of low contact resistance. Solders have low melting points in comparison to metals to be joined. That results when solder is heated, molten solder wets the metallic parts, spreads and joints. Mainly classification of solder is done into two group i.e. soft solder and hard solder. Soft solders have decreased melting point and decreased tensile strength. Soft solders generally included tin lead alloys and silver based composition. Some soldering techniques are given below:
1) Soft Soldering.
2) Hard Soldering.
3) Braze Soldering.
4) Silver Soldering.
5) Lead Based Soldering.
6) Lead Free Soldering.

\section{FINAL TESTING}

In this system we connected the battery to power the power supply section, battery is the backup for elevator system and it is the power supply block. In this way we produce the 5 Volt supply and 12 Volt supply to the various peripheral devices. The 5 Volt supply is connected to components like LCD, Limit switch, Relay $1 \& 2$, etc. The output of relay is connected to solenoid lock for locking the lift system, it will protect the lift when thread is disconnected from the lift. The motor driver IC L298 is control DC gear motor (12 Volt). WiFi module is communication between the internet and android application, it helps to take the data from android application and give to the Node MCU Microcontroller.

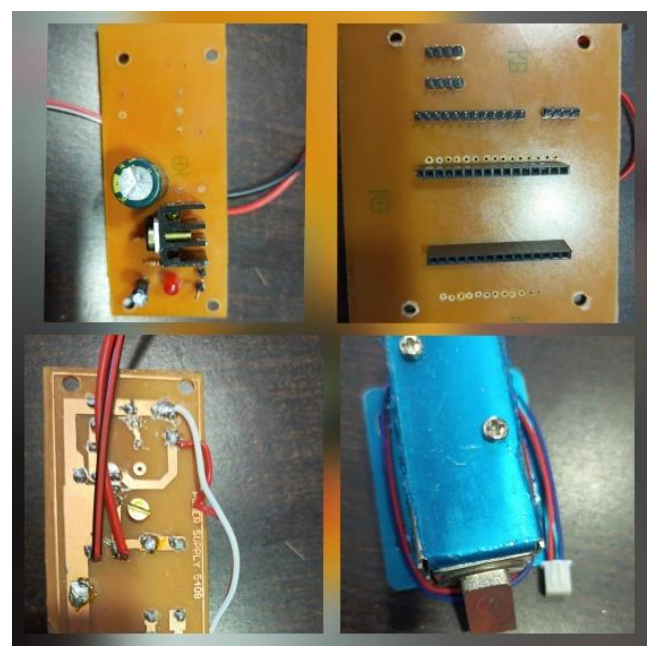

Fig. 7 Instruments Assembling

LCD will show the direction of lift whether it is in upward or in downward direction depending upon the input from the android application. Limit switch acts as a feedback sensor of the lift, when thread is break then limit switch is pressed and output of limit switch becomes high, it is connected to Node MCU Microcontroller. It sense that the thread is not available or it is break, then after Node MCU takes decision and gives command to relay and all the solenoid locks will turns on and the lift is blocked.

\section{PERIODIC INSPECTION AND TEST}

\section{$\rightarrow$ Authorized Person to Make Inspection and Test}

The Inspector must satisfy all the qualification requirements required. Inspectors as well as inspection Super wiser must be certified by an authorized organization. [7]

\section{$\rightarrow$ Frequency of Inspection and Test}

The frequency of periodic inspection and test shall be established by the authority having jurisdiction. [7]

\section{$\rightarrow$ Making Safety Devices Inactive}

No person shall at any time make any required protection tool or electric defensive tool ineffective, besides where essential throughout tests and inspections. Such devices will be restored to their ordinary running situation in conformity with the relevant necessities earlier to returning the gadgets to service. [7]

\section{$\rightarrow$ Test Tags}

A Metallic Tag with the relevant code requirements and date of performance and call of the individual or company acting the test, will be established within side the system control room or system space for all periodic tests. [7]

\section{ADVANTAGES}

1) Collision problem due to breaking of thread is avoided.

2) Wireless Remote Control operation.

3) Delivers protection to people as well as goods.

4) Secure and enhanced system.

5) Use of IoT technology.

6) Backup protection using Battery along with Generator.

\section{CONCLUSION}

Nowadays, Elevators become the essential needs of human being but there is a lot of risk involved while going through elevators. Faulty system or the system not consisting safety parameter results serious injury to a person or some time loss of life.

With the help of "Smart Protective System of Elevators" the accidents in the elevator may reduce. The sensors used in this system detect the faults and chances of occurrence of 
accidents gets reduced. IP cameras continuously monitoring the thread as well as sensors and reflects the collected data on display. In small apartments or complex, they don't have generators or DG sets, in this situation power off means stacking between floors, in this situation this system works as an alternative or supportive system which helps one to reach the floor he/she wish.

During this Corona pandemic situation we always avoid physical touch at public places, the android app 'Blynk' is so effective in such a way that one can call the lift without actually touching the buttons of the lift. Most of additional safety requirements and tools are newly added in this system or field of safety of Elevators. Overall conclusion is that by using this system the risks in the elevators gets reduced as compared to current situation and one absolutely feel safe while going via elevator.

\section{REFERENCE}

[1] O. M. Shete, D. V. Shete, S. G. Pise . A survey paper on design and control of an elevator for smart city application. "International Journal of Advanced Research in Electrical, Electronics and Instrumentation Engineering"

[2] Shri madhwa Vadiraja Institute of Technology and Management, Udupi, India "International Journal of Advance Research in Computer and Communication Engineering ISO 3297:2007 Certified"

[3] T. D. Barkand. "Elevator Safety: Give The Miner Brake". U.S. Department of labor Mine safety and health administration, Bruceton safety technology Centre.

[4] H. Joshi, R. Bhokare. "Control and Automation: Safety Improvement in Elevator."

[5] Dan Shi, Bixi Xu. IOP conference series: Material Science and Engineering 366 012076. "Intelligent Elevator control and Safety Monitoring System."

[6] Ms. P. D. Duggal, Ms. P. M. Palpankar, Mrs. A. Y. Fadnis (Department of Electrical Engineering D.B.A.C.E.R, Nagpur University, India). (Department of Electrical Engineering, Y.C.C.E, Nagpur University, India).

[7] American Society of Mechanical Engineers. "Safety Code for Elevators and Escalators". An American National Standard ASME A17.1-2007/CSA B44-07.

[8] Z. Wuqiao. "Research on Quantitative Computation Method of Elevator Safety Accident Based on Risk Perception". 2017 International Conference on Industrial Informatics-Computing Technology, Intelligent Technology, Industrial Information Integration.

[9] T. Palekar, R. Tesa Jose, G. Nanche, R. Joshi. "Study and Simulation of Five-Story Elevator Controller Using VHDL". Proceedings of the Third International
Conference on Trends in Electronics and Informatics (ICOEI 2019) 